\title{
Alignment of Divergent Organizational Cultures in IT Public-Private Partnerships
}

\author{
Public-private partnerships (PPP) are increasingly important for the provision and utilization \\ of information technology (IT) in the public sector. However, IT PPPs are difficult to realize, \\ as examples, such as the Toll Collect project, confirm. In this study, we analyze the cultural \\ differences of public sector and private sector organizations and the alignment of cultural \\ differences for effective collaboration in IT PPPs. In addition, we identify specific \\ management procedures that are necessary to address organizational culture differences \\ for succeeding with IT PPPs.
}

DOI 10.1007/s12599-012-0213-9

\section{The Authors \\ M.Sc., Dipl.-Kfm. (FH) \\ Oliver Marschollek (凶) \\ Prof. Dr. Roman Beck \\ Institute of Information Systems \\ Goethe University Frankfurt \\ Grüneburgplatz 1 \\ 60323 Frankfurt am Main \\ Germany \\ marschollek@wiwi.uni-frankfurt.de \\ rbeck@wiwi.uni-frankfurt.de}

Received: 2011-07-14

Accepted: 2012-02-27

Accepted after three revisions by

Prof. Dr. Heinzl.

Published online: 2012-04-26

This article is also available in German in print and via http://www. wirtschaftsinformatik.de: Marschollek O, Beck R (2012) Harmonisierung divergierender organisationaler Kulturen in öffentlichprivaten IT-Partnerschaften. WIRTSCHAFTSINFORMATIK. doi:10.1007/ s11576-012-0320-8.

A previous version of this paper has already been published in the Proceedings of the European Conference on Information Systems in 2011 (Marschollek 2011).
Electronic Supplementary Material The online version of this article (doi: 10.1007/s12599-012-0213-9) contains supplementary material, which is available to authorized users.

(C) Gabler Verlag 2012

\section{Introduction}

In the past decades, public agencies have increasingly engaged in public-private partnerships (PPP) to realize large infrastructure projects (Kwak et al. 2009), which is a form of cooperation that entails long-term sharing of resources, risks, and objectives (Maskin and Tirole 2008). However, there is a considerable number of public infrastructure projects realized in the context of a PPP, which exceeded estimated costs and time schedules (e.g., Klijn 2009; Yuan et al. 2009). In comparison to public infrastructure projects, IT projects are even more difficult to realize because of an often limited understanding about the inherent complexity and uncertainty of IS developments and implementations of engineers and managers in charge (Flyvbjerg and Budzier 2011; Nelson 2007). The realization of IT projects in cooperation between public and private organizations even increases this inherent project complexity due to divergent interests of participating stakeholder groups which may lead to misunderstandings, conflicts, and even project failure (Buhl and Meier 2011; Jost et al. 2005). Prior research on large-scale public-private IT projects examined failures and turnaround mechanisms using an escalation of commitment perspective (Drummond 1996, 1998; Keil and Robey 1999; Montealegre and Keil 2000) or analyzed the role of key actors' interests (McGrath 2002). However, these studies did not conduct an in-depth analysis of the specific cultural context of IT PPPs or examine how to succeed with establishing a sustainable IT PPP.

To understand the challenges of publicprivate collaboration and how to succeed with IT PPPs, we conducted an interpretive case study of an IT PPP in Germany involving a large IT service provider and a German city. The goal was to operate, maintain, and renew the IT infrastructure of the city and improve the cost transparency of IT services. Despite some initial collaboration difficulties, public and private parties finally managed to establish a sustainable partnership. Therefore, this case offered an opportunity to answer two key research questions:

(1) How do public- and private-side organizational cultures affect publicprivate collaboration in IT PPPs?

(2) How can successful public-private collaborations in IT PPPs be established?

In the following sections, we provide the theoretical foundations of the study and explain the applied research approach. After a brief case description, we present the results of our theory-building case study on public-private collaboration in IT PPPs. Finally, we discuss our theoretical and practical contributions and provide future research directions. 


\section{Theoretical Background}

Since the 1960s, PPPs became an increasingly popular alterative (Pongsiri 2002) for providing public services with higher quality at lower costs or to finance public infrastructure projects (Grimsey and Lewis 2002; Reijniers 1994; Smyth and Edkins 2007). While the technical challenges of public IT projects are very similar to the ones usually found in other industries (Nelson 2007), the reasons for organizational challenges and tensions in public-private collaboration can be attributed to different interests and corporate cultures of public and private parties (Reijniers 1994). These cultural differences can cause ongoing misunderstandings and conflicts, which may prevent the development of a sustainable PPP (Jost et al. 2005). While public agencies have to act in the interest of the general public and private companies strive to improve their market value, in a PPP both parties need to develop complementary objectives (Scharle 2002). In particular, the development of an effective partnership approach, focusing on public- and privateside goals, as well as common project goals, necessitates the establishment of a shared culture based on mutual trust, commitment, and understanding (Bresnen and Marshall 2000; van Marrewijk 2007; van Marrewijk et al. 2008). However, although extant literature examined the effect of public and private sector organizational cultures on public-private collaboration, the differences of publicand private-side organizational cultures as well as how to develop a shared publicprivate culture to succeed with IT PPPs is still unclear.

In our case study, we observed collaboration difficulties of public and private sector organizations due to different ways of thinking and acting. According to Schein (1990), different organizational values and practices established over time for coping with organizational challenges can be regarded as manifestation of an organizational culture. From an institutional perspective, these values and practices are developed and legitimized based on the regulative (e.g., laws), normative (e.g., shared norms), and culturalcognitive (e.g., shared beliefs) elements of an institutional environment, such as an organization (Scott 2001). To specify which values and practices shall be pursued within an organization, institutional logics provide the organizing principles that offer formal and informal rules for guiding organizational behavior (Thornton and Ocasio 1999). In an IT PPP, which can be regarded as a community of organizations frequently cooperating with each other (Scott 2001), different institutional logics may be at play which trigger divergent organizational behaviors and hence can cause clashes of organizational cultures. Accordingly, institutional logics theory provides an adequate lens to analyze the pursued norms, values, and practices of different organizations cooperating in an IT PPP context (Friedland and Alford 1991; Scott 1987).

As the extant literature on interorganizational cooperation illustrates, effective partnership arrangements require cultural alignment as precondition for partnership success (Bresnen and Marshall 2000; Fuller and Vassie 2002). Therefore, we investigated the organizational culture differences of public and private sector organizations, and illustrate how they were overcome by the development and legitimization of partnership norms and practices. Prior management research on organizational culture differences in inter-organizational cooperations concentrated on the analysis of the effect of differences in national and organizational culture on international joint venture performance (Pothukuchi et al. 2002), or on international mergers and acquisitions (Badrtalei and Bates 2007; Sarala and Vaara 2010). Sirmon and Lane (2004) expanded the consideration of cultural differences by including professional culture differences and evaluated how national, organizational, and professional culture differences influence international alliance performance. Information systems research extended these insights by analyzing the effects of organizational and interpersonal culture differences on the success of offshore projects (Rai et al. 2009). The results of our case study, however, provide first insights on organizational culture differences of public and private sector organizations and the norms and practices of a sustainable IT PPP.

\section{Research Methodology}

In our exploratory case study, we applied an interpretive stance (Walsham 1995a, 1995b) to understand the socially constructed challenges (Orlikowski and Baroudi 1991) of collaboration in IT PPPs. Using grounded theory techniques, we analyzed the subjective interpretations and meanings of interviewees about IT PPP management and developed theoretical explanations (Goulding 1998) of public- and private-side organizational culture differences.

To apply grounded theory techniques to our data collection and analysis procedure (Glaser 1978; Glaser and Strauss 1967), we conducted interviews using a semi-structured guideline with openended questions about partnership history, development, and management. For coding and to develop a case study database, we used Atlas.ti software (Muhr 2008). Both authors took notes during the interviews, but only one author coded the interviews. Open, lineby-line coding of initial interviews, followed by discussion of resulting initial insights, supported the inductive identification of core themes. These initial insights facilitated the specification of our interview guidelines, and helped us identify additional interviewees since we asked each respondent for other experts (similar to the principle of interaction, Klein and Myers 1999). To gain a holistic picture of IT PPPs, we interviewed participants from public administration, politics, and private industry with different roles in the partnership (vendor versus client) and positions in the hierarchy (top-level versus operative IT service management) to ensure insights from different perspectives on IT PPP management (Table 1).

Initial interviewee selection was guided by the theoretical sampling process of the grounded theory method, which deals with the joint collection, coding, and analysis of data (Glaser and Holton 2004). From interviews conducted during January-November 2010, 37 recordings, lasting from 57 minutes to 2 hours and 48 minutes, resulted in 3,689 audio minutes and 877 transcribed pages. In addition, we collected secondary material, such as service level reports and press articles, to increase our understanding of the IT PPP and its environment. The 98 press articles helped us examine the course of action of the partnership (see the course of action illustrated according to the amount of press articles in Electronics Supplementary Material). The sampling process supported critical reflection on the core themes and the PPP context, comparable to the principle of contextualization (Klein and Myers 1999). During the combined data collection and analysis procedure, we finally 
Table 1 Affiliation of interviewees and number of interviews

\begin{tabular}{|l|l|c|}
\hline Organizational Affiliation & \multicolumn{1}{|c|}{ Hierarchical Affiliation } & Number of Interviews \\
\hline \multirow{3}{*}{ Public Administration } & - City department & 9 \\
& - Administrative office & 6 \\
& - Staff council & 1 \\
\hline \multirow{2}{*}{ Politics } & - Mayor & 3 \\
\hline \multirow{3}{*}{ Private IT Service Provider } & - City council & 5 \\
& - Top management & 8 \\
\hline Public IT Service Provider & - Project management & 1 \\
\hline Public Consulting Service & - Top management & 2 \\
\hline
\end{tabular}

reached theoretical saturation when further interviews did not reveal any new aspects on organizational culture differences. At that point, we started to integrate our findings to derive theoretical contributions (Glaser 1978).

The data analysis using Glaserian grounded theory techniques encompasses three coding steps: open, selective, and theoretical coding (Urquhart et al. 2010). Open, line-by-line coding of the interviews enabled us to identify interviewee statements explaining public- and private-side culture differences. These statements were descriptively labeled according to the observed phenomena (e.g., citizen orientation). The interviews revealed that divergent cultures affected not only the establishment of a sustainable partnership but also how the parties defined IT PPP success. After reviewing the open codes, we started selective coding of the identified core themes to consolidate the previously descriptive open codes to categories on a higher conceptual level (e.g., public logic). By triangulating different perceptions, we tried to remain sensitive to different views among the participants, according to the principles of multiple interpretations and suspicion (Klein and Myers 1999). In addition to identifying the core themes inductively, we screened prior literature for a meta-theoretical lens to explain the elements of organizational cultures and their effect on collaboration in IT PPPs. That is, extant literature was not as preconceived framework for theory verification (Urquhart et al. 2010) but rather supported the conceptualization of our core categories and their single attributes, while also providing additional data for comparisons with primary and secondary data. Using this lens, we examined possible contradictions between theoretical preconceptions and new research findings - similar to the principles of abstraction, generalization, and dialogical reasoning (Klein and $\mathrm{My}$ ers 1999). For example, we were able to identify that public administration managers and politicians adhere to different IT PPP success criteria, while extant literature does not distinguish into different organizational cultures on public side (Christensen et al. 2007).

Our conceptualization and triangulation efforts (following the constant comparative method) enabled us to relate our selective codes to the core themes, as explained by the propositions in our model (Glaser and Holton 2004). This final theoretical coding analysis step, conducted through our meta-theoretical lens, revealed new concepts in the PPP context (e.g., partnership management procedures) that can moderate the influence of public- and private-side logics on a sustainable IT PPP. The result of our study thus is a model that conceptualizes public- and private-side organizational culture differences and their effect on collaboration in IT PPPs.

\section{Case Description}

The case study deals with the cooperation of the internal IT department of a German city (more than 270,000 inhabitants) with an internationally operating IT service provider. The city's intention was to ensure the IT infrastructure operated according to a defined quality standard with regular modernization, as well as to improve cost transparency and efficiency and transfer economic risk to the private partner.

After an official tendering procedure, beginning in 2003, the new joint company was founded at the end of 2004 (Heinzl and Sinß 1993) and started operating on January 1st, 2005. The IT
PPP was contracted for a ten-year period, from 2005 to 2014, at costs of more than 80 million Euros. Merging the city's former internal IT department into the new company included the transfer of more than 60 employees, though they remained employed by the city, which retained disciplinary authority. The PPP needs to provide IT services for more than 3,300 users in seven departments and 25 administrative offices in 200 locations distributed across the whole city - including 5,000 IT (e.g., personal computers) and 5,200 telecommunication devices, 5,000 network access ports, and 200 administrative IT procedures.

Initial difficulties in public-private collaboration arose due to incompatible goals, expectations, and operating procedures, yet public administration, political, and private industry members jointly developed a sustainable collaboration mode. Recognizing and understanding public- and private-side organizational culture differences and the corresponding organizational behaviors (guided by divergent logics), while developing management procedures, facilitated a sustainable partnership (Fig. 1). In the following, we discuss the characteristics of public- and private-side logics and their effect on public-private collaboration; we also explain how the parties managed to succeed with their partnership approach.

\section{Case Analysis}

\subsection{Divergent Public and Private Logics}

Initial challenges of public-private collaboration stemmed from different organizational cultures, consisting of different norms, values and practices, which defined ways of thinking and acting. Divergent mindsets, knowledge bases, and organizational structures can be regarded as manifestations of these unique norms, values and practices: On the one hand, public agency's core norm was service provision for the general public, as legitimated by the responsibility of a public agency to fulfill its legal mandate. On the other hand, earning money for shareholders shaped the goal orientation of private organizations as their essential private norm. In contrast with public organizations, private organizations need to provide agreed upon IT services by a specified time, quality, and costs, as defined in service-level agreements (SLA). 
Fig. 1 Succeeding with public-private collaboration in IT PPPs

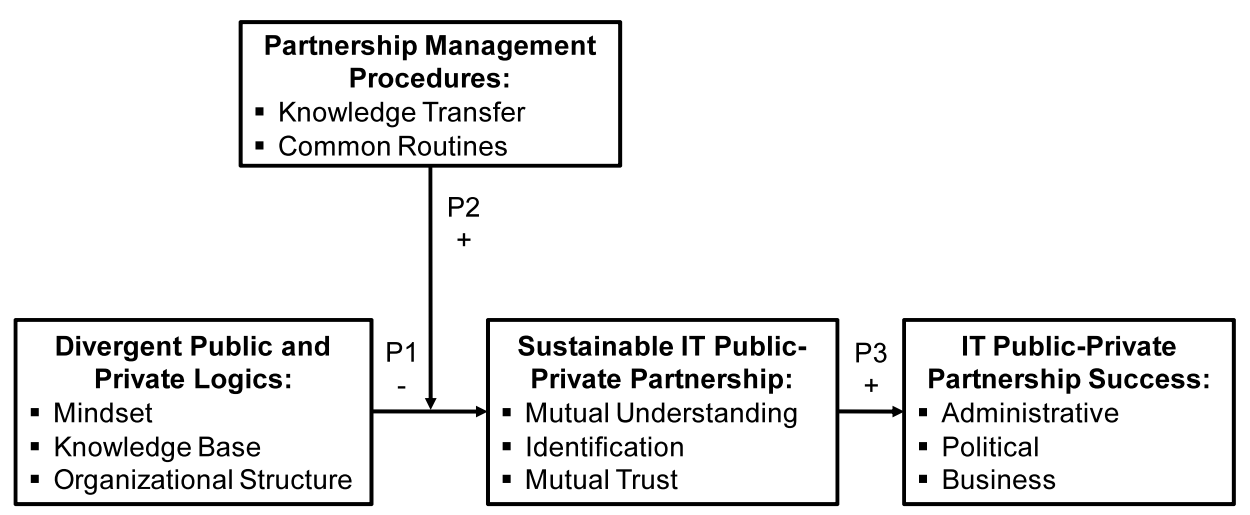

Monetary penalties accrue if SLAs are violated. However, public employees of the analyzed joint company were not familiar with this performance orientation of the private side, even as they were evaluated according to this private norm. An external senior consultant, with collaboration experience with public agencies, political parties, and private industry, noted:

"Public employees, who were being judged according to private rules, and private employees, who were confronted with the mentality of public administration, experienced a cultural shock. They could not understand why their partner was acting in that way, because they were not used to their way of thinking."

Beyond different ways to provide services, public and private mindsets reflect different legal contexts, such that they are subject to differential scrutiny. Public administration work is bound to constitutional procedures embedded in legal norms, such as negotiating a fixed fiscal budget for two years. Private organizations are legally required to document their business processes for auditing companies, but they may shift their budgets to different purposes on short notice. These different norms and practices initially led to conflicts: The joint IT projects needed a considerable amount of time to prepare, which neither met the expectations of the private partner nor satisfied the public partner with regard to short-term IT innovations. As a politician on the city council, who experienced the cultural clashes as a member of the IT PPP supervisory board, described it:

"At the beginning, cooperation between the parties was difficult because the private party was trying to achieve a result, but it was permanently slowed down by constitutional requirements from the public party, which resulted in a lack of understanding on the private side."

In addition to the public service motivation, public employees needed to comply with legal norms, which shaped their mindsets. Unlike private employees, with their private norm of economic success, focusing on career opportunities and monetary gratifications, public employees mainly strive for a stable work environment, which fosters their identification with public administration work. Thus, the manager of the city's former IT department, responsible for network infrastructure management in the IT PPP, indicated:

"A colleague of mine has switched to public administration to gain a stable, local activity field. $\mathrm{He}$ wanted to make sure he could spend evenings with his family. This is a motivation for a lot of people to choose public administration work, which conflicts with the basic motivation of joining a private company."

Initial clashes of these divergent organizational cultures were driven by different mindsets but also by unfamiliarity with the other side's expertise, which led to misunderstandings. The private side could not understand legally driven requirements of administrative services; the public side was not used to industrybased services oriented toward cost efficiency. Thus, public-side users were accustomed to free-of-charge IT services from the internal IT department, so they anticipated unlimited IT services from the new joint company. They lacked experience with scope and cost calculations for, say, desktop services, which involved more than acquisition costs for a personal computer. At the same time, the private party knew little about the diversity of administrative processes and their requirements. These divergent practices created a continuous struggle within collaboration processes, because both sides repeatedly had to clarify their differential knowledge and expertise. For example, a private account manager of the joint company had experienced knowledge exchange processes within the PPP but was not accustomed to the need of clarifying standard business knowledge:

"If I buy a personal computer without paying for support services, there will be no support when I have problems with the computer, no replacement of a damaged device, no insurance against theft. The public side was not used to this standard industry scope and the costs of IT services. We, on the other hand, could not imagine that there was the need to constantly explain what was common knowledge for us."

Public- and private-side logics diverged not only in terms of the knowledge base of their different service types, but also according to their embedded IT procedures. The private IT service provider acted in accordance with documented, structured procedures from the IT infrastructure library (ITIL). The formerly public IT department had historically grown and legitimated implicit procedures, oriented towards the public principle of providing unlimited IT services to all city departments. That is, both parties had adopted adequate IT procedures for solving IT problems, in line with their situations, as summarized by a manager for network infrastructure of the former city IT department:

"Our city culture for IT procedures was not adjusted to ITIL. When we 
had a problem, all relevant people met immediately and developed a solution in an unbureaucratic way, by considering the individual requirements of all stakeholders. For us, it was unusual to structure IT procedures according to specific roles and tasks, because in our department, everybody provided all possible IT services to colleagues."

Furthermore, public-private organizational culture differences were caused by divergent organizational structures and the corresponding decision-making processes, which fundamentally determined public- and private-side organizational behavior. For example, a public administration needs to align the divergent interests of all stakeholders and convince them that a proposed approach is adequate. This consensus-oriented structure recognizes the diversity of stakeholder groups, such as political parties and administrative departments that must be committed to the joint goal; which is legitimated by their autonomous status. Moreover, public employees tend to feel responsible for meeting citizens' needs and therefore for ensuring the adequacy of administrative procedures. This common public practice surprised the private side, which was focused on economic aspects. Private industry's embedded organizational structure relied more on topdown delegation and responsibility, such that single entities aligned their activities with the overall goal of satisfying shareholder needs. The intensity of top-down decisions, the need for alignment, and the degree of coordination on the private side was not expected by the public partner. The astonishment on the public side about common private-side structures was expressed by a manager of the city's finance department:

I was surprised that the private employees needed to align so many activities with their headquarters and were not very independent in their decisions. This was new for us; we thought that in private industry, head managers could decide more independently compared with our structures.

Finally, public- and private-side organizational structures differed in their temporal affiliation. The job security status of public employees enabled public agencies to ensure continuous working

Table 2 Specific differences between public and private logics

\begin{tabular}{|l|l|l|}
\hline $\begin{array}{l}\text { Categories of Public } \\
\text { and Private Logics }\end{array}$ & \multicolumn{1}{|c|}{ Public Logic } & \multicolumn{1}{c|}{ Private Logic } \\
\hline Mindset & $\begin{array}{l}\text { - Services for the public } \\
\text { - Constitutional procedures } \\
\text { - Job security orientation }\end{array}$ & $\begin{array}{l}\text { - Performance orientation } \\
\text { - Audit-proof procedures }\end{array}$ \\
\hline Knowledge Base & $\begin{array}{l}\text { - Administrative services } \\
\text { - Implicit IT procedures }\end{array}$ & $\begin{array}{l}\text { - Industry services } \\
\text { - Explicit IT procedures }\end{array}$ \\
\hline $\begin{array}{l}\text { Organizational } \\
\text { Structure }\end{array}$ & $\begin{array}{l}\text { - Consensus structure } \\
\text { - Continuity orientation }\end{array}$ & $\begin{array}{l}\text { Top-down structure } \\
\text { Project orientation }\end{array}$ \\
\hline
\end{tabular}

relationships and support the establishment of personal identification with and a feeling of responsibility for public services. Establishing a sustainable partnership required continuous engagement to nurture the relationships and develop a collaboration mode. The basic norm of profit maximization and the corresponding value of career development, however, fostered a short-term project orientation on the private side. Such an orientation was not adequate for establishing a sustainable partnership, because short-term engagement in the IT PPP left little room for developing responsibility for or identification with services to be provided to the general public. A leading private manager for IT operations of the joint company commented on this challenge, who substituted the previous manager for IT operations on short notice:

"I can understand that it was not easy for public employees to develop a trustworthy relationship with us, because on our side, there were so many staff changes, which made it necessary to become acquainted with the new staff over and over again."

Divergent public- and private-side norms and practices, embedded in their respective logics (Table 2), guided organizational behaviors of public and private sector organizations. A lack of knowledge about or acknowledgment of differences in public- and private-side mindsets, knowledge bases, and organizational structures led to continuous misunderstandings and conflicts that impeded a sustainable partnership based on mutual understanding, identification, and mutual trust. On the basis of these findings, we propose:

Proposition 1 Divergent public and private logics, consisting of different mindsets, knowledge bases, and organizational structures, influence public- and privateside organizational behaviors and thereby lead to misunderstandings and conflicts in IT PPPs.

\subsection{Partnership Management Procedures}

To reduce continuous misunderstandings and conflicts that resulted from divergent logics and to establish a sustainable partnership, the different parties needed to develop mutual understanding and appreciation of each other's mindsets, knowledge bases, and organizational structures. For example, the private party needed to explain and communicate its basic norms, to enable the public side to understand private-side behavior and develop collaboration modes. A private account manager of the joint company, whose collaboration strategy was based on intensive communication, explained this way of thinking and acting:

\footnotetext{
"The client and our partners cannot understand our motivation without any explanation. We need to create transparency not only about what is important to us, but also, why it is important to have a specific governance structure for IT."
}

In addition to transferring knowledge about divergent mindsets, it was important to clarify the different organizational structures and decision-making processes, then offer support in the effort to understand the requirements of, e.g., administrative versus industry IT procedures. Public IT management had never measured SLAs or controlled an IT service provider. To enable it to do so, it needed transparency regarding the underlying norms, values and practices. To achieve sufficient partnership conditions, including identification and mutual trust, both parties had to develop 
and legitimate common routines that balanced their divergent norms and values. Therefore, new information services and regular meetings were introduced to ensure all participating stakeholders knew the joint goals of and new developments within the joint company, which helped increase the basic level of mutual understanding. Involving every party in the new partnership routines improved their sense of responsibility and identification with the norms and practices of the IT PPP. Furthermore, establishing and legitimating common routines supported trust development, because both parties developed a general belief in their partner's intention to succeed with the joint company. As a means to align stakeholders and discuss the orientation, as well as developments, of the IT PPP, the public side recommended a supervisory board with members from each stakeholder party. Frequent meetings of this board supported trust development, because all stakeholders received continuous information about the current state of the IT PPP, which facilitated successful governance of the new joint company. A manager of project acquisitions from the private vendor, who was actively involved in the tendering procedure and later governing of the company as member of the board, recognized:

"The public side encouraged us to trust them with establishing a supervisory board because they manage every company of the city this way. Although a supervisory board with more than 20 participants for a company of around 60 employees was strange for us, we learned that this kind of governance was helpful for aligning the different stakeholder parties."

These partnership management procedures diminished initial misunderstandings and conflicts by transferring knowledge about underlying norms and values, as well as the corresponding organizational behavior through constant explanations and the establishment of legitimated common routines. Therefore, we propose:

Proposition 2 Partnership management procedures that encourage continuous knowledge transfer about public- and private-side norms and practices and the establishment of common routines of the IT PPP diminish misunderstandings and conflicts arising from divergent publicand private-side logics.

\subsection{Establishing a Sustainable IT Public-Private Partnership}

By understanding divergent institutional logics, both parties developed a collaboration mode that enabled them to understand thought processes and corresponding behaviors of their partner. Both parties also identified with the negotiated goals, which fostered a feeling of loyalty and responsibility for partnership norms. Establishing and legitimating common routines and integrating stakeholder parties into these processes furthered partnership development, because the partners recognized their common interest: IT PPP success. This progress was described by a manager of the private vendor, who was involved in the negotiations about the mode of collaboration:

"Listening intensively to each other and illustrating partnership goals and developments in, for example, the monthly reports of key performance indicators - we thus were able to create transparency about IT PPP progress and our intentions. This increased identification with the goal orientation and the tasks of this company."

Understanding not only supported the negotiation of joint goals and the development of common routines but also increased confidence in mutual recommendations for certain organizational structures. For example, the private side was familiar with steering boards, but establishing a supervisory board for a small company of only 60 employees seemed unusual. In addition, establishing a reporting system based on SLAs was very uncommon for the public side, because the provision of IT services had never been controlled by the use of negotiated contracts before. Nevertheless, both parties made concessions about leading the IT PPP and thereby emphasized their willingness to collaborate. Furthermore, acting as reliable partners facilitated the establishment of mutual trust, which is of tremendous importance in partnerships with heterogeneous organizational cultures; it encourages a joint belief in the success of the partnership. Thus, a private account manager of the joint company explained the situation when collaborating with a public client:

"To develop a trustworthy relation in a situation in which two conflicting organizational cultures collide, it is of particular importance to be reliable. Therefore, you not only need to disclose your motivation and deliver what you promised but also, in case of any delay, you have to explain why you cannot deliver as promised. Then a public client will still consider you a reliable partner."

In summary, establishing mutual understanding, fostering identification with the joint company, and developing mutual trust were important for success in this IT PPP. Negotiating joint compromises about different stakeholder goals and legitimizing new common routines provided symbols of a sustainable partnership. These compromises were not only essential for establishing a sustainable IT PPP, but also for accomplishing the goals of the different stakeholder groups. We propose:

Proposition 3 Establishing a sustainable IT PPP, characterized by mutual understanding, identification, and mutual trust, enables the accomplishment of divergent success criteria from administrative, political, and business perspectives.

\subsection{IT Public-Private Partnership Success}

Although daily collaborations were succeeding and the parties were gaining familiarity with each other, negotiating compromises about their joint goal orientation remained critical, because the partners had divergent perspectives on their partnership success criteria (Table 3 ). These divergent perspectives reflected the different norms and values of public- and private-side organizational cultures. Public administration managers, politicians, and business managers have different perceptions about IT PPP success criteria: Public administration managers primarily concentrate on legal compliance; they do not want to be vulnerable to lawsuits, in line with their adherence to constitutional procedures and job security. Furthermore, according to the norm of public service provision, public administration aims at the efficient use of their existing financial resources, stemming from taxpayers. Thus, the renewal of the IT infrastructure, which enabled public administration to improve the quality of its administrative processes, represented a major issue, since it was critical for delivering 
Table 3 Divergent success criteria in IT public-private partnerships

\begin{tabular}{|l|l|}
\hline $\begin{array}{l}\text { Perspectives on } \\
\text { IT PPP Success }\end{array}$ & \multicolumn{1}{c|}{ Hierarchy of Success Criteria } \\
\hline Administrative & $\begin{array}{l}\text { (1) Legal compliance } \\
\text { (2) More efficient use of existing resources } \\
\text { (3) Improved quality of public services }\end{array}$ \\
\hline Political & $\begin{array}{l}\text { (1) Re-election } \\
\text { (2) Positive perception of partnership success in the general public } \\
\text { (3) Advancing modernization of public administration structures }\end{array}$ \\
\hline Business & $\begin{array}{l}\text { (1) Profit orientation } \\
\text { (2) Increase of market share in the public sector }\end{array}$ \\
\hline
\end{tabular}

public services. A manager from the private side noted, as he became more acquainted with public-side norms through negotiations with the mayor and other department managers:

"The primary goal of local authorities is to ensure closeness to citizens and to realize administrative procedures, such as tax collection and ticket processing, more efficiently."

Politicians, another public stakeholder party, mainly focused on their need for re-election, which required successes of their political programs. Therefore, they needed the general public (citizens and media) to perceive the IT PPP as successful - or at least not sense any disruption in public administration services. Furthermore, politicians concentrated on the modernization of public administration structures, in the form of an adequate technological infrastructure, innovation and management know-how, and the capability to improve administrative structures. The perception of IT PPP success by the general public, including the efficient use of taxpayers' money, also reflected the mindset of providing services for the general public. These political success criteria were illuminated by a manager of the new joint company, responsible for exchanges with and detailed explanations about the state and development of the IT PPP to each stakeholder group:

\footnotetext{
"The political case deals with the image of a politician. A politician is obliged to improve the city's financial situation in a socially acceptable way and guarantee public service provision, which in our case was realized through better technological equipment that ensured administrative efficiency and innovativeness."
}

Finally, from a business perspective, the primary ambition of a private IT service provider is to increase profits. By delivering IT services according to negotiated costs, time, and quality criteria, it could underline its reliability and thus perhaps acquire more local authorities as partners, to increase its market share. These success criteria are congruent with the private norm of performance orientation, as revealed by a manager of technical infrastructure operations of the new joint company:

"Our main goal is to earn money with a customer. Therefore, we provide our services in time, in quality, and within the negotiated costs. In addition, we tried to expand this successful model of IT PPP collaboration to other local authorities."

Being aware of the divergent success criteria of the stakeholder groups and actively negotiating compromises about their joint goals finally enabled successful IT PPP realization.

\section{Discussion}

\subsection{Implications for Research and Practice}

In our IT PPP case study, we concentrated on examining differences of public and private sector organizational cultures and how the parties managed to develop a shared public-private culture to succeed with the IT PPP. Different public and private sector cultures have already been identified as source of collaboration difficulties in PPPs (Reijniers 1994). Prior research on large-scale IT projects driven by public and private sector organizations examined the reasons for IT project failure and the mechanisms that triggered project turnaround (Drummond 1996, 1998; Keil and Robey 1999; Montealegre and Keil 2000) or analyzed the role of alternative interests among key stakeholders and how they stabilized over time (McGrath 2002). However, these studies did not conduct an in-depth analysis of the existing divergent organizational cultures in the IT PPP context or investigate the development of a shared public-private culture as antecedent of IT PPP success. With our case analysis, we contribute to the domain of IT PPPs closing this gap and illustrate the basic norms of public and private sector organizations (observed as part of the category mindset), i.e., being responsible for the needs of the general public versus satisfying shareholders' needs, and complying with the legal norms of the different contexts (i.e., constitutional and audit-proof procedures). According to Schein (1990), the norms of the different institutional environments can be classified into the category "underlying assumptions" of an organizational culture (conceptualized in Table 4) since they determine thought processes and behaviors of public and private sector organizations. Furthermore, backed by institutional logics theory, our study is the first to disclose which values (illustrated by the third dimension of the category mindset), practices (illustrated by the categories knowledge base and organizational structure), and goals (embodied by the different hierarchies of success criteria) are pursued by public and private sector organizations according to their different institutional norms. Comparing the conceptualized categories of public and private logics with the levels of organizational culture, the dimensions "job security orientation" and "career orientation" can be referred to the organizational culture level "values". That is since both dimensions are derived from the underlying assumptions of responsibility for public services and satisfying shareholders' needs as well as compliance with the different legal norms. In addition, the identified categories "knowledge base" and "organizational structure" can be assigned to the level of organizational culture "artifacts" since these categories comprise practices, which are visually observable. Table 4 summarizes the classification of the observed public and private logics into the levels of organizational culture according Schein (1990).

In general, effective partnership arrangements in inter-organizational co- 
Table 4 Classification of public and private logics based on Schein's (1990) levels of culture

\begin{tabular}{|c|c|c|c|}
\hline $\begin{array}{l}\text { Categories of Public } \\
\text { and Private Logics }\end{array}$ & Public Logic & Private Logic & $\begin{array}{c}\text { Level of } \\
\text { Organizational } \\
\text { Culture }\end{array}$ \\
\hline \multirow[t]{2}{*}{ Mindset } & \multirow{2}{*}{$\begin{array}{l}\text { - Services for the public } \\
\text { - Constitutional procedures } \\
\text { - Job security orientation }\end{array}$} & \multirow{2}{*}{$\begin{array}{l}\text { - Performance orientation } \\
\text { - Audit-proof procedures } \\
\text { - Career orientation }\end{array}$} & $\begin{array}{l}\text { Underlying } \\
\text { Assumptions }\end{array}$ \\
\hline & & & Values \\
\hline Knowledge Base & $\begin{array}{l}\text { - Administrative services } \\
\text { - Implicit IT procedures }\end{array}$ & $\begin{array}{l}\text { - Industry services } \\
\text { - Explicit IT procedures }\end{array}$ & \multirow{2}{*}{ Artefacts } \\
\hline $\begin{array}{l}\text { Organizational } \\
\text { Structure }\end{array}$ & $\begin{array}{l}\text { - Consensus structure } \\
\text { - Continuity orientation }\end{array}$ & $\begin{array}{l}\text { - Top-down structure } \\
\text { - Project orientation }\end{array}$ & \\
\hline
\end{tabular}

operations require the alignment of organizational culture differences (Bresnen and Marshall 2000; Fuller and Vassie 2002). Prior management research in this context analyzed the effect of national, organizational, professional, and interpersonal culture differences on international cooperations (Badrtalei and Bates 2007; Pothukuchi et al. 2002; Rai et al. 2009; Sarala and Vaara 2010; Sirmon and Lane 2004). However, research on organizational culture differences within IT projects in general and within IT PPPs in particular is still missing. This case study is one of the first contributions in that area examining how public and private parties managed to align their different organizational cultures in an IT partnership by the development and legitimization of a partnership norm and practices. In particular, using an institutional logics perspective, the results of our case study show that aligning public and private sector organizational cultures to succeed with the IT PPP was enabled by acknowledging differences of public- and privateside norms, as well as their corresponding values, goals, and practices. Furthermore, to establish a sustainable IT PPP, it was necessary to constantly balance divergent public- and private-side norms and to develop as well as legitimize common practices. Balancing public- and privateside norms through constant negotiations led to the establishment of a joint partnership norm. This joint partnership norm was the basis for a successful partnership arrangement since public- and private-side goals, as well as common partnership goals were pursued. The constant balancing of public- and privateside norms and the establishment of partnership practices supported the process of cultural alignment and the successful transition of public and private sector employees into the partnership organization. Cultural alignment was accompanied by the development of mutual un- derstanding, identification with the partnership approach, and mutual trust in the positive intentions of the partner. Within our analysis and by the use of institutional logics theory, we explicated the differences of public and private sector organizational cultures (e.g., mindsets, knowledge bases, and organizational structures), their interplay in collaborations, as well as the adaptation and alignment of cultural differences to create a partnership norm (embodied by a constant balancing of public- and privateside norms) and practices (illustrated by partnership management procedures).

Our case analysis does not only provide insights to research, but also provides recommendations for practice. The results illustrate how public and private sector organizations succeeded with the transition of public and private sector employees into a partnership organization and the management of different organizational cultures. In particular, to establish sustainable IT PPPs, IT PPP managers need to be aware of and understand public-private organizational culture differences. In such an inter-organizational cooperation, an open-minded collaboration environment is crucial to acknowledge differences in organizational cultures. In doing so, misunderstandings and misaligned expectations can be prevented. The development of a collaborative environment can be achieved by satisfying public- and private-side interests through negotiating complementary objectives and cultivating regular meetings between the partners to openly exchange issues and expectations. In our case, these open exchanges facilitated continuous knowledge exchange and learning which created a culture where critical issues could be addressed openly. In addition to establishing a collaborative environment, IT PPP managers need to include all stakeholder groups in the partnership development process. Thereby, identification and commitment with the partnership endeavor can be enhanced, which further supports the active engagement of both partners in partnership processes and joint projects' realization.

\subsection{Limitations}

Apart from the insights to research and the implications for practice, in terms of generalizability, the findings of this study are restricted to IT PPPs. In addition, within this single-case study, research aspects, such as the alignment of cultural differences only emerging over time, were retrospectively investigated accompanying the studied IT PPP for around one year. Since the findings are based on a single-case study of an IT PPP in Germany, which was conducted at a municipal administrative level, the observed management practices for succeeding with IT PPPs might be casespecific and accordingly different in other research settings, such as other countries or on other administrative levels. However, by inductively identifying the management practices necessary to align the different organizational cultures from the gathered data and constantly comparing interviewers' and interviewees' perceptions with extant literature, we believe that we were able to provide new theoretical explanations about organizational culture differences.

Based on the limitations of this singlecase study, future research should accompany an IT PPP project over its complete lifecycle to explore the temporal aspects of partnership development and maintenance in every single partnership phase. In the studied case, IT PPP success was largely dependent on the managers in charge. Therefore, further research should also investigate the leadership capabilities and behaviors that are important for bridging the cultural divide. Furthermore, it would be desirable to conduct a cross-case analysis of IT PPPs in different countries and on different administrative levels (e.g., federal, state, and municipal level) to provide a robustness check of the findings.

\section{Conclusions}

This paper contributes to the domain of IT PPPs by explaining the existing divergent organizational cultures in the IT PPP context and the development of a 
shared public-private culture to succeed with IT PPPs. We contribute to the theoretical domain of organizational culture differences by providing evidence of the different dimensions of public- and private-side organizational cultures and the alignment of different organizational cultures in an IT partnership by the development and legitimization of a partnership norm as well as the necessary partnership practices. The overall implication for IT PPP research is that establishing a sustainable IT PPP requires the awareness and understanding of publicprivate organizational culture differences and the development of a mode of collaboration to negotiate joint goals and procedures.

\section{Acknowledgement}

The authors thankfully appreciate the vital participation of the practitioners in this research. This work was developed as part of a research project at Goethe University Frankfurt. We are indebted to and gratefully acknowledge the financial support of ISPRAT e.V. Any opinions, findings, conclusions, or recommendations expressed in this paper are those of the authors and do not necessarily reflect the views of ISPRAT e.V. or its supporting partners.

\section{References}

Badrtalei J, Bates DL (2007) Effect of organizational cultures on mergers and acquisitions: the case of DaimlerChrysler. Int J Manag 24(2):303-317

Bresnen M, Marshall N (2000) Partnering in construction: a critical review of issues, problems and dilemmas. Constr Manag Econ 18(2):229-237

Buhl HU, Meier MC (2011) The responsibility of business and information systems engineering in large-scale IT projects, symptoms, diagnosis, and therapy. Bus Inf Syst Eng 3(2):61-64

Christensen T, Lgreid P, Roness PG, Røvik KA (2007) Organization theory and the public sector, instrument, culture and myth. Routledge, Milton Park

Drummond $H$ (1996) The politics of risk: trials and tribulations of the Taurus project. J Inf Technol 11(4):347-357

Drummond $\mathrm{H}$ (1998) Is escalation always irrational? Organ Stud 19(6):911-929

Flyvbjerg B, Budzier A (2011) Why your IT project may be riskier than you think. Harv Bus Rev 89(9):23-25

Friedland R, Alford RR (1991) Bringing society back in: symbols, practices, and institutional contradictions. In: Powell WW DiMaggio PJ (eds) The new institutionalism in organizational analysis. University of Chicago, Chicago, pp 232-263
Fuller CW, Vassie LH (2002) Assessing the maturity and alignment of organisational cultures in partnership arrangements. Empl Relat 24(5):540-555

Glaser BG (1978) Theoretical sensitivity. Sociology, Mill Valley

Glaser BG, Holton J (2004) Remodeling grounded theory. Forum: Qual Soc Res 5(2)

Glaser BG, Strauss AL (1967) The discovery of grounded theory: strategies for qualitative research. Aldine, Chicago

Goulding C (1998) Grounded theory: the missing methodology on the interpretivist agenda. Qual Mark Res 1(1):50-57

Grimsey D, Lewis MK (2002) Evaluating the risks of public private partnerships for infrastructure projects. Int J Proj Manag 20(2):107-118

Heinzl A, Sinß M (1993) Kooperationen zur zwischenbetrieblichen Entwicklung von Anwendungssystemen. Inf Manag 2:60-67

Jost G, Dawson M, Shaw D (2005) Private sector consortia working for a public sector client - factors that build successful relationship: lessons from the UK. Eur Manag $J$ 23(3):336-350

Keil M, Robey D (1999) Turning around troubled software projects: an exploratory study of the deescalation of commitment to failing courses of action. J Manag Inf Syst 15(4):63-87

Klein HK, Myers MD (1999) A set of principles for conducting and evaluating interpretive field studies in information systems. Manag Inf Syst Q 23(1):67-93

Klijn E-H (2009) Public-private partnerships in the Netherlands: policy, projects and lessons. Econ Aff 29(1):26-32

Kwak YH, Chih Y, Ibbs CW (2009) Towards a comprehensive understanding of public private partnerships for infrastructure development. Calif Manag Rev 51(2):51-78

Marschollek O (2011) "Nobody wins, but nobody loses either" - understanding different institutional logics in IT public-private partnerships. In: Proc 19th European conference on information system, Helsinki

Maskin E, Tirole J (2008) Public-private partnerships and government spending limits. Int J Ind Organ 26(2):412-420

McGrath K (2002) The golden circle: a way of arguing and acting about technology in the London ambulance service. Eur J Inf Syst 11(4):251-266

Montealegre R, Keil M (2000) De-escalating information technology projects: lessons from the Denver international airport. Manag Inf Syst Q 24(3):417-447

Muhr T (2008) Atlas.ti - the knowledge workbench, scientific software development. Berlin

Nelson RR (2007) IT project management: infamous failures, classic mistakes, and best practices. MIS Q Exec 6(2):67-78

Orlikowski WJ, Baroudi JJ (1991) Studying information technology in organizations: research approaches and assumptions. Inf Syst Res 2(1):1-28

Pongsiri N (2002) Regulation and publicprivate partnerships. Int J Public Manag 15(6):487-495

Pothukuchi V, Damanpour F, Choi J, Chen CC, Park SH (2002) National and organizational culture differences and international joint venture performance. J Int Bus Stud 33(2):243-265

Rai A, Maruping LM, Venkatesh V (2009) Offshore information systems project success: the role of social embeddedness and cultural characteristics. Manag Inf Syst $Q$ 33(3):617-641

\section{Abstract}

O.Oliver Marschollek, Roman Beck

\section{Alignment of Divergent Organizational Cultures in IT Public-Private Partnerships}

The cooperation of public and private sector organizations is a viable option for decision makers in the public sector for improving information technology (IT) infrastructures, acquiring innovation, and increasing management know-how. Effective partnering in public-private partnerships (PPP) is difficult though, because the involved stakeholder groups have divergent interests and organizational cultures. Using institutional logics as meta-theoretical lens, this exploratory, interpretive case study analyzes an IT PPP in Germany. The results reveal public-and private-side organizational culture differences and how the partners aligned their cultural differences by the development and legitimization of a partnership norm as well as the necessary partnership practices. The case analysis also illustrates how public sector and private sector organizations succeeded with the transition of public sector and private sector employees into a partnership organization and the management of different organizational cultures.

Keywords: IT public-private partnerships, Institutional logics, Case study research 
Reijniers JJAM (1994) Organization of publicprivate partnership projects, the timely prevention of pitfalls. Int J Proj Manag 12(3):137-142

Sarala RM, Vaara E (2010) Cultural differences, convergence, and crossvergence as explanations of knowledge transfer in international acquisitions. J Int Bus Stud 41(8):1365-1390

Scharle P (2002) Public-private partnership (PPP) as a social game. Innovation 15(3):227-252

Schein EH (1990) Organizational culture. Am Psychol 45(2):109-119

Scott WR (1987) The adolescence of institutional theory. Adm Sci Q 32(4):493-511

Scott WR (2001) Institutions and organizations. Sage, Thousand Oaks
Sirmon DG, Lane PJ (2004) A model of cultural differences and international alliance performance. J Int Bus Stud 35(4):306-319

Smyth H, Edkins A (2007) Relationship management in the management of PFI/PPP projects in the UK. Int J Proj Manag 25(3):232-240

Thornton PH, Ocasio W (1999) Institutional logics and the historical contingency of power in organizations: executive succession in the higher education publishing in dustry, 1958-1990. Am J Sociol 105(3):801843

Urquhart C, Lehmann H, Myers MD (2010) Putting the 'theory' back into grounded theory: guidelines for grounded theory studies in information systems. Inf Syst J 20(4):357-38 van Marrewijk A (2007) Managing project culture: the case of the Environ megaproject. Int J Proj Manag 25(3):290-299

van Marrewijk A, Clegg SR, Pitsis TS, Veenswijk M (2008) Managing public-private megaprojects: paradoxes, complexity, and project design. Int J Proj Manag 26(6): 591-600

Walsham G (1995a) The emergence of interpretivism in IS research. Inf Syst Res 6(4):376-394

Walsham G (1995b) Interpretive case studies in IS research: nature and method. Eur J Inf Syst 4(2):74-81

Yuan J, Zeng AY, Skibniewski MJ, Li Q (2009) Selection of performance objectives and key performance indicators in publicprivate partnership projects to achieve value for money. Constr Manag Econ 27(3):253-270 